TITLE:

\title{
A NEW HYDROID SPECIES OF CYTAEIS, WITH SOME REMARKS ON THE INTERRELATIONSHIPS IN THE FILIFERA
}

$\operatorname{AUTHOR}(\mathrm{S})$ :

Uchida, Tohru

CITATION:

Uchida, Tohru. A NEW HYDROID SPECIES OF CYTAEIS, WITH SOME REMARKS ON THE INTERRELATIONSHIPS IN THE FILIFERA. PUBLICATIONS OF THE SETO MARINE BIOLOGICAL LABORATORY 1964, 12(2): 133-144

\section{ISSUE DATE:}

1964-10-15

URL:

http://hdl.handle.net/2433/175362

RIGHT: 


\title{
A NEW HYDROID SPECIES OF CYTAEIS, WITH SOME REMARKS ON THE INTERRELATIONSHIPS IN THE FILIFERA
}

\author{
TOHRU UCHIDA \\ Zoological Institute, Faculty of Science \\ Hokkaido University
}

With 8 Text-figures

In 1927 the writer published a paper on Japanese Anthomedusae, and herein described Cytaeis japonica as a new species on the basis of specimens collected from Misaki and Seto. In this paper he reported young medusae with medusa-buds, which was identified with a query at that time with $C$. japonica (in lines 20 and 38-40 on page 216), and further alluded to the identification of Cytaeis vulgaris by MAAs (1909) from Japan with these young medusae. Next year upon receiving a paper from KRAMP (1928) describing a new medusa, Podocoryne simplex from Japan, the present writer learned that the young medusae with medusa-buds were not young forms of Cytaeis japonica but nothing but Podocoryne simplex. In 1930 the writer examined MaAs' specimens which were collected in Japan and preserved in the Zoologische Sammlung in Munich and made clear that the young medusae with medusa-buds are precisely Podocoryne simplex. Besides, he could find no specimen of the genus Cytaeis in this collection. Since then he reported Podocoryne simplex from several localities, from Asamushi to Amakusa, in Japan (UchidA, 1938 \& 1938a). Meanwhile, KomaI (1931) reported the polyp and young medusae of Cytatis japonica from Misaki. The problem of Cytaeis japonica seemed thus to have been settled.

Recently KR.AMP (1961) published the list of medusae of the world and regarded C. japonica as a synonym of C. tetrastyla, because the Japanese species has medusa-buds like the latter, basing on UchIDA's note (1927). He seemed to overlook UCHIDA's paper (1930) published in Germany. REes (1962) published a fine paper on the Cytaeidae and revised species in the family. In this paper he followed KRAMP (1961) in the identification of C. japonica with C. tetrastyla, because he also overlooked UCHIDA's paper (1930). He reported there two new species from Japan; Cytaeis uchidae and $C$. nuda on the basis of specimens sent by H. M. the Emperor of Japan. He identified some of these polyps and

Publ. Seto Mar. Biol. Lab., XII (2), 1964. (Article 8) 
medusae with the hydroid reported by KomaI (1932) as C. japonica and instituted a new species $C$. uchidae for them. The descriptions of $C$. uchidae, however, nearly apply to specimens of $C$. japonica with the exception of slight difference in number of oral tentacles. Therefore, the writer wrote to REes about Podocoryne simplex which was wrongly mixed in the original description of $C$. japonica.

After writing to REEs, the writer was given a precious suggestion by $\mathrm{H}$. $\mathrm{M}$. the Emperor, that there exists a medusa belonging to Cytaeis, which has larger ovaries and more oral tentacles than those of C. uchidce, and that the medusa liberates from a hydropolyp different from the latter polyp. Through the generosity of H. M. the Emperor the writer could study on polyps and medusae of Cytaeis preserved or in breeding in the Biological Laboratory of the Imperial Palace and reached the conclusion that the writer's original diagnosis (1927) of Cytaeis japonica is mainly based on specimens of $C$. uchidae Ress but includes also some features of Podocoryne simplex and new species of Cytaeis which will be reported here. Such being the case, the writer proposes to abandon the name Cytaeis japonica and to institute a new species Cytaeis imperialis $\mathrm{n}$. sp. for new hydroid collected and first observed by $\mathrm{H}$. M. the Emperor, at whose suggestion this investigation was commenced and by whose kindness the paper has taken shape.

\section{Cytaeis imperialis n. sp.}

(Figs. 1-5)

The following descriptions are based on preserved specimens as well as living ones reared in the Biological Laboratory of the Imperial Palace. These specimens were all collected in the vicinity of Hayama in Sagami Bay and are preserved in the biological laboratory above mentioned.

Hydropolyps: Colonies cover the shell of the gastropod Nassarius (Zeuxis) coelatus which is of ten collected at the depths 60-120 meters in Hiramon near Hayama. The stolons are smoothly grown, running in grooves of the gastropod shell, frequently forming a loose net-work. Polyps arising singly from stolons, generally $0.4-1 \mathrm{~mm}$ high, each composed of a long hydrocaulus and a slightly widened hydranth (Fig. 1). They extend over $1 \mathrm{~mm}$, but are not so long as in those of $C$. uchidae and have, by no means, perisarcal cups at their bases. The polyps have a distal whorl of 4 to 8 tentacles around a bluntly-conical hypostome. These tentacles extend over $1 \mathrm{~mm}$ and are armed with distinct nematocysts which are arranged in rossary-like form. In living state, longer tentacles are often lifted above and shorter tentacles are extended obliquely downwards. Hydrocaulus reddish brown, and epistome and tentacles white. Medusa-buds are borne singly on short stalks arising directly from the hydrorhiza. They are $0.17-0.25 \mathrm{~mm}$ high and pyriform in shape. 
Medusae: Young medusae just liberated, $0.75 \mathrm{~mm}$ high and $0.7 \mathrm{~mm}$ wide, with universally thin jelly. Exumbrella sprinkled with minute nematocyst clusters. The manubrium is slightly widened at base, with 4 perradial oral tentacles just above the roundish quadrate mouth. Peduncle above the manubrium not well-developed. From each base of 4 radial canals, there arises a tentacle which is very extensile with an enlargement at the terminal portion. Tentacle bulbs and manubrium slightly brownish in colour. No trace of gonads on the manubrium. In a medusa, 4 days after liberation, $0.9 \mathrm{~mm}$ high and $0.9 \mathrm{~mm}$ wide, tentacle bulbs became enlarged, and their endoderm became distinctly pigmented brown (Fig. 2). Oral tentacles still 4 in number. No gonads developed. A medusa, 7 days after liberation, is nearly of the same size, but its peduncle, though short, is clearly developed and the manubrium has

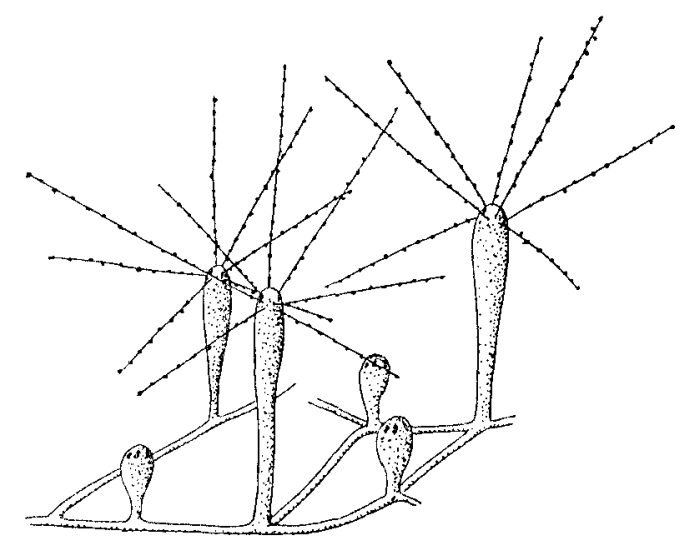

Fig. 1. A part of colony of Cytaeis imperialis n. sp.

become broad, with 4 oral tentacles (Fig. 3). The tentacle bulbs are enlarged and pigmented. Tentacles are extensile, with a terminal enlargement. The shaft of them is armed with nematocysts which are arranged more or less in circlets with the exception of the proximal portion. Exumbrella sprinkled with nematocyst clusters. Gonads do not yet appear. A medusa, 14 days after liberation, is $1 \mathrm{~mm}$ high and $1 \mathrm{~mm}$ wide and provided with 7 oral tentacles; 4 perradial and 3 interradial. In this medusa gonads are developed, especially in the middle part of the manubrium. Peduncle clearly developed above the manubrium. Second series of oral tentacles appeared in the interradial parts of manubrium just above the level of the first perradial series. Tentaclebulbs enlarged and distinctly pigmented. When the medusa becomes 20-23 days old, it attains $1.5 \mathrm{~mm}$ in diameter and becomes to have 10-15 oral tentacles (Fig. 4). In medusae of this stage, the gonads are well-developed 


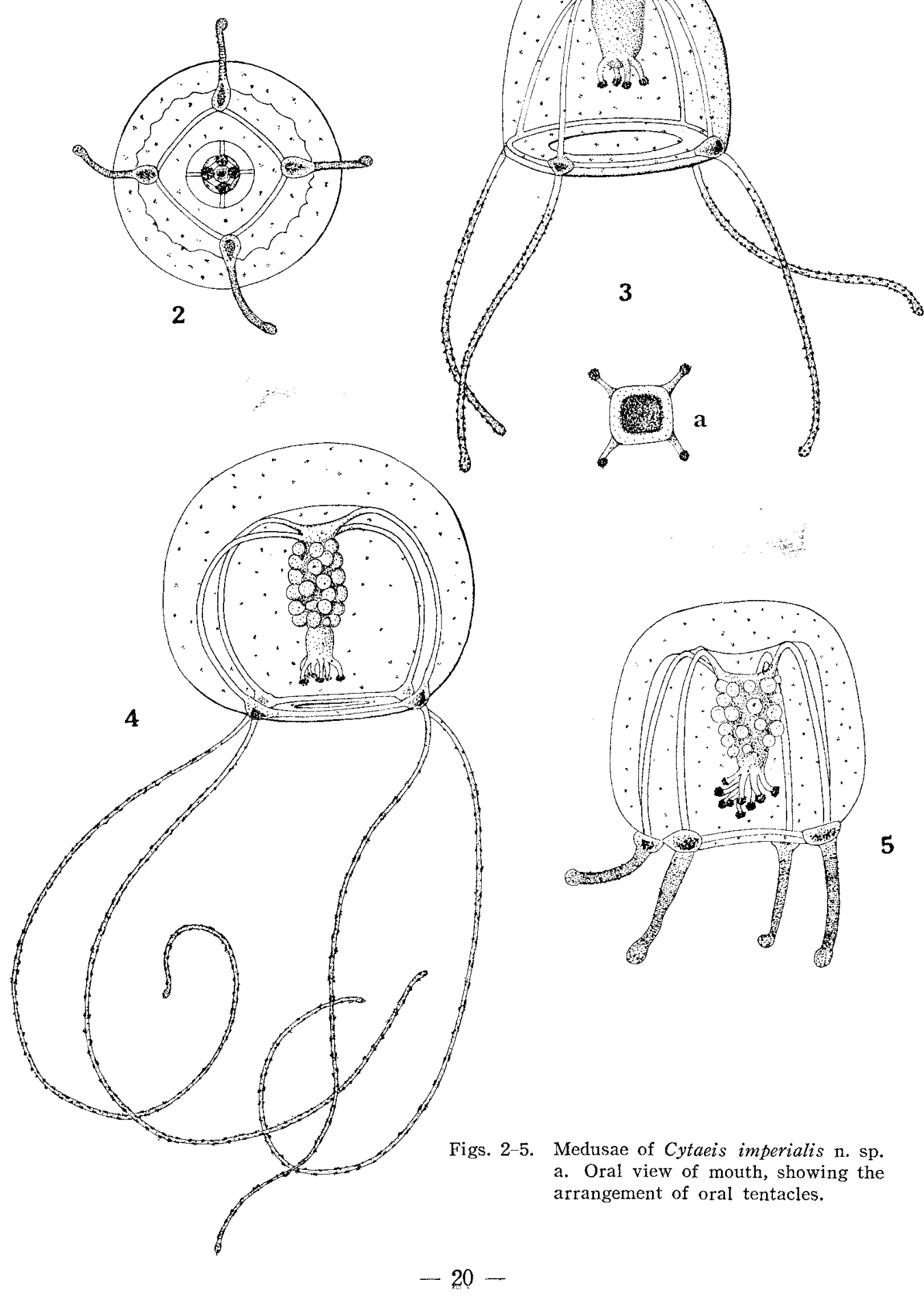


from the summit of manubrium downwards, leaving the distal part free from them. The gonads encircle the manubrium, large ova being arranged in 6-7 longitudinal rows. Exumbrella sprinkled with nematocyst clusters. Tentacles are very extensile, with a terminal enlargement and many nematocyst batteries. In a contracted state (Fig. 5) the terminal enlargement of tentacles is obviously perceived.

In reference to the age and the number of oral tentacles of the medusa, the following measurements are made by Mr. T. SHimizu of the Biological Laboratory.

Specimens of Cytaeis imperialis n. sp. collected at Hiramon.

\begin{tabular}{|c|c|c|c|c|c|}
\hline $\begin{array}{l}\text { Date of } \\
\text { liberation }\end{array}$ & $\begin{array}{l}\text { Date of } \\
\text { fixation }\end{array}$ & $\begin{array}{c}\text { Diameter of } \\
\text { medusae }\end{array}$ & $\begin{array}{c}\text { Number of oral } \\
\text { tentacles }\end{array}$ & Individuals & Gonads \\
\hline Nov. 21,1962 & $\begin{array}{l}\text { Dec. } 5,1962 \\
\text { Dec. } 15,1962 \\
\text { Dec. } 27,1962 \\
\text { Dec. } 28,1962\end{array}$ & $\begin{array}{l}\text { about } 1 \mathrm{~mm} \\
\text { about } 1.5 \mathrm{~mm} \\
\text { about } 1.5 \mathrm{~mm} \\
\text { about } 1.5 \mathrm{~mm}\end{array}$ & $\begin{array}{c}7-8 \\
6-7 \\
10-15 \\
9 \text {-more than } 10\end{array}$ & $\begin{array}{l}2 \\
2 \\
4 \\
4\end{array}$ & $\begin{array}{l}\text { developed } \\
\text { developed } \\
\text { developed } \\
\text { developed }\end{array}$ \\
\hline
\end{tabular}

Remark: The new species, though somewhat similar to Cytaeis uchidae, is distinctly different from the latter both in the polyp and medusa.

The hydropolyp of $C$. imperialis $n$. sp. lacks always the cup-like periderm which exists at the base of the hydropolyp of C. uchidae. Tentacles of the former have nematocysts more regularly arranged than in the latter. The colonies of $C$. imperialis n. sp. grow only on the shell of the gastropod, Nassarius (Zeuxis) coelatus which dwells in rather deeper depths, while the colonies of C. uchidae cover the shells of Nassarius (Niotha) livescens or Nassarius (Hinia) festivus which are commonly collected near the tidal lines.

When the medusa of C. imperialis n. sp. is compared with that of C. uchidae, there can be found the following differences: 1) Young medusae of the former just liberated have no sign of gonads, whereas young medusae of the latter have always well-developed gonads at liberation. 2) The medusa of the former species becomes to have gonads at the stage when it has more than 7 oral tentacles which increase to 12-15 afterward. But in the latter medusa no more than 7 oral tentacles have ever been observed. 3) The medusa of $C$. imperialis n. sp. has by no means apical niche or its remnant even in the young, but the medusa of $C$. uchidae has generally remnants of the apical niche in the jelly throughout the life.

For the reference the writer will give the summarized list of medusae which were reported as belonging to the genus Cytaeis in Japan. 


\section{Podocoryne simplex KRAMP, 1928}

Podocoryne simplex: Kramp, 1928, p. 45, fig. 20 ; UCHIDA, 1930, p. 331 ; UCHidA, 1938, p. 39-40 ; UCHIDA, $1938 \mathrm{a}$, p. 145.

Cytaeis vulgaris: MAAS, 1909 , p. 8.

Cytaeis japonica (in part): UCHIDA, 1927, p. 215-217.

This seems to be the first medusa as belonging to Cytaeis from Japan. MaAs (1909) reported Cytaeis vulgaris from Japan but did not describe any species of Podocoryne. These specimens were re-examined by UcHIDA (1930) in Munich. As the present writer could not find any medusae belonging to the genus Cytaeis in MAAs' collection, he identified MAAs' Cytaeis vulgaris with this species. The writer himself also misidentified the medusa with young forms of Cytaeis japonica (1927). The species has only two opposite tentacles in younger stages and bears young medusa-buds on its manubrium. In medusae with four marginal tentacles, equal in length, medusa-buds are still attached to the manubrium.

\section{Cytaeis tetrastyla Eschscholtz, 1829}

Cytaeis tetrastyla: KRAMP, 1961, p. 63-64.

In his list Kramp identified Cytaeis japonica Uchida with this cosmopolitan species, and ReEs (1961) followed his identification. Recently through the kindness of Dr. KRAmp the present writer could examine several specimens of $C$. tetrastyla from the Philippines and the Atlantic, which are far larger and have more number of oral tentacles than the Japanese medusae hitherto known as C. japonica in Japan (=Cytaeis uchidae REES). C. tetrastyla is quite different from the Japanese species and has never been collected in Japanese waters.

\section{Cytaeis uchidae REES, 1962}

Cytaeis uchidae: REEs, 1962, p. 383-387, figs. 1-3.

Cytaeis japonica: UCHIDA (in part), 1927, p. 215-217, fig. 39, pl.1, fig. 7 ; KomaI, 1931, p. 255258, fig. A-C.

UCHIDA's original descriptions (1927) are based on three species, C. uchidae, C. imperialis n. sp. and Podocoryne simplex but mainly on specimens belonging to the first species. The figures which he gives in his paper (1927) are drawn from C. uchidae. The figure in Pl. 1 denoted a male specimen and the textfigure 39 shows a well-developed female. These medusae have the apical niche in the jelly, and this is a marked character of the species.

Though young medusae of the species have been described in detail by ReEs (1962), the present writer will give here a supplementary description, especially on old medusae. Young medusae begin to appear in the middle of 
May, and well-developed medusae are found at Misaki in the end of July. So far the writer's observations go, these medusae have all the remnant of apical niche, which is indicated by a group of minute particles in jelly. Exumbrellar nematocyst clusters are distinct and become sometimes enlarged and conspicuous in old medusae. The opening of velum is very small. The shape of umbrella, peduncle of manuburium and marginal tentacles are quite similar to those of $C$. imperialis n. sp.. The marginal tentacles are short and terminated in contracted state, but have the terminal enlargement in extensile state. The nematocyst rings are slightly indistinct in comparison with those of the new form. Gonads have rather less number of ova in well-developed medusae, when compared with those of the new species, although some medusae have fairly numerous ova as is shown in Fig. 6. These medusae coincide with the text-figure 37 given in the writer's orginal work (1927). In one of these medusae, the writer counted 7 oral tentacles; 4 perradial and 3 interradial (Fig. 6a). The interradial ones arise from higher level of the manubrium from the perradial ones and have probably a tendency to be increased up to 4 in number. So far as the examined specimens are concerned, no medusae have oral tentacles more than 7 . The presence of the remnant of apical niche, less number of oral ten-

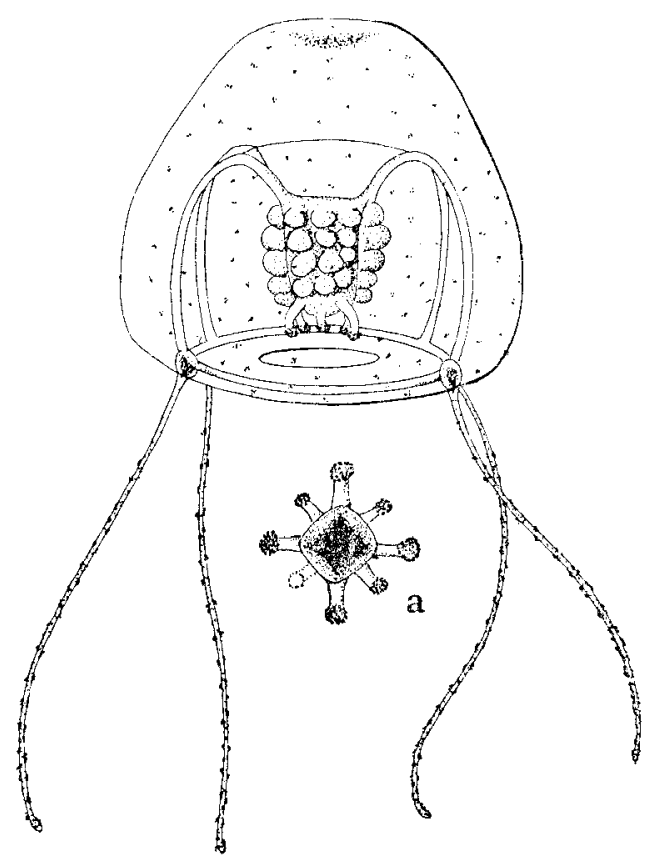

Fig. 6. Well-developed medusa of Cytaeis uchidae Rees.

a. Oral view of mouth, showing the arrangement of oral tentacles. tacles and prematurity of gonads are the characters sharply distinguished from those of $C$. imperialis. Moreover, the gastropod hosts of the polyp are different from that of $C$. imperialis as stated above. This is the commonest species of Cytaeis in Japan.

\section{Cytaeis nuda REES, 1962}

Cytaeis nuda: REES, 1962, p. 387-390, figs. 4-7.

The species is well described by ReEs basing on two colonies sent to him 
by H. M. the Emperor of Japan who collected them in a sponge grown on the gastropod Fusinus perplexus at Hayama, Sagami Bay.

\section{Interrelationships among the hydroid group Filifera}

In 1957 ReEs published a paper on "evolutionary trends in the classification of capitate hydroids and medusae". The present writer will give here the notes on interrelationships between filiferous hydroids and medusae. For the hydroid study, one must take into consideration both hydropolyps and hydromedusae (or sporosacs) in this group. Therefore, the following families such as Bythotiaridae, Polyorchidae and Spirocodonidae have been excluded in this investigation, because in these families only medusae are known and polyps are not yet observed. The Proboscidactylidae, of which the systematic position is not clear, have been reserved for future study. Such being the case, the following 7 families have been studied; e.g. Clavidae, Cytaeidae, Bougainvilliidae, Eudendriidae, Rathkeidae, Hydractiniidae, Pandeidae.

In respect to the polyps, much importance must be attached to their morphology itself, but not to the character whether they are solitary or colonial. However the form of colonies, creeping or arboreous, shows somewhat the declinations possessed by respective families. Viewed from the morphology of polyps, there can be seen two types, quite distinct from each other: one is a Clava-like type, with irregularly distributed filiform tentacles, and the other is a so-called "Perigonimus"-type with a whorl of filiform tentacles. The Clavidae alone belong to the first type and other 6 families belong to the second one. Therefore, the Clavidae seem to be distinctly separated from other families. In 1956 REES published a paper on a revision of the genus Perigonimus which is not valid at present. According to him, among 40 species which were reported as belonged to Perigonimus, 17 species belong to the Bougainvilliidae, 13 species to the Pandeidae, and 1 species each to the Cytaeidae, the Eudendriidae, the Proboscidoctylidae and the Haleciidae (Thecata). The Hydractiniidae have also polyps of the Perigonimus-type but are characterized by polymorphism, so they were distinguished from Perigonimus. As shown above, the Bougainvilliidae and Pandeidae have been of ten classified into Perigonimus on the similarity of their polyps. But these two families are clearly different from each other in the morphology of their medusae. The medusae of Pandeidae have hollow marginal tentacles which are distributed on the bell margin in the definite sequence, while the medusae of Bougainvilliidae have solid tentacles grouped in the perradius or also in the interradius. Moreover, the latter have oral tentacles which are missing in the former. The hollow marginal tentacles are present only in the Pandeidae among these six families. Besides, the Pandeidae seem to have many divergent medusae 


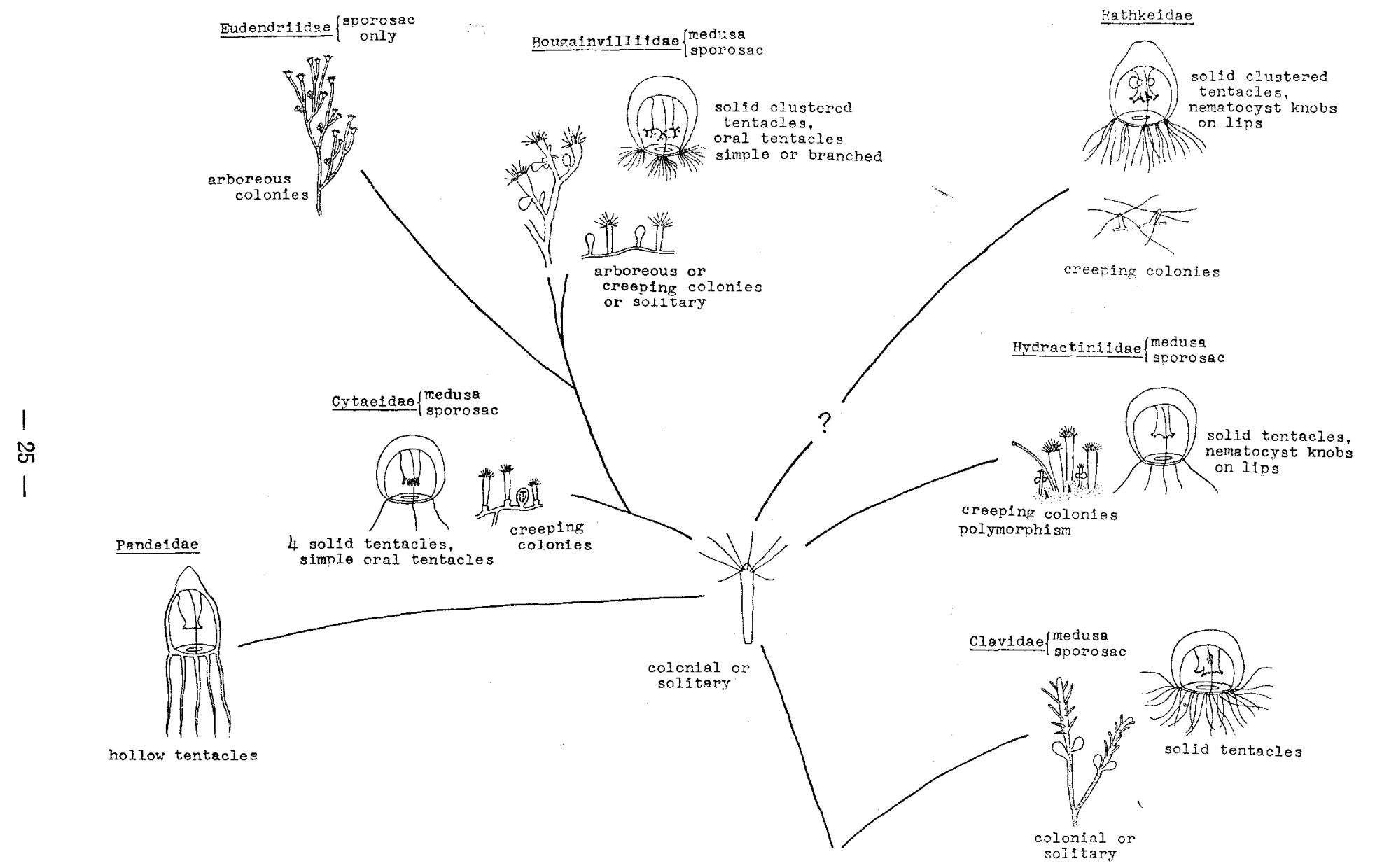

Fig. 7. A diagrammatic representation of interrelationships of families in the Filifera. 
and stand in separate position from other families here considered. The Pandeidae will surely be subdivided in the future, when their life-histories have been made clear.

Of the remaining five families the Cytaeidae seem to be the most primitive. Their polyps form a creeping colony, with stolons from which polyps and gonosomes singly arise. The medusae have only 4 solid marginal tentacles, roundish oral lips, unbranched oral tentacles and gonads encircling the manubrium. Some forms have sporosacs. The Bougainvilliidae seem to stand in more differentiated position than the Cytaeidae and have several trends of evolution. The hydroid colonies of Bougainvilliidae have two distinct forms; one creeping and the other arboreous. Besides, Nemopsis dofleini has the
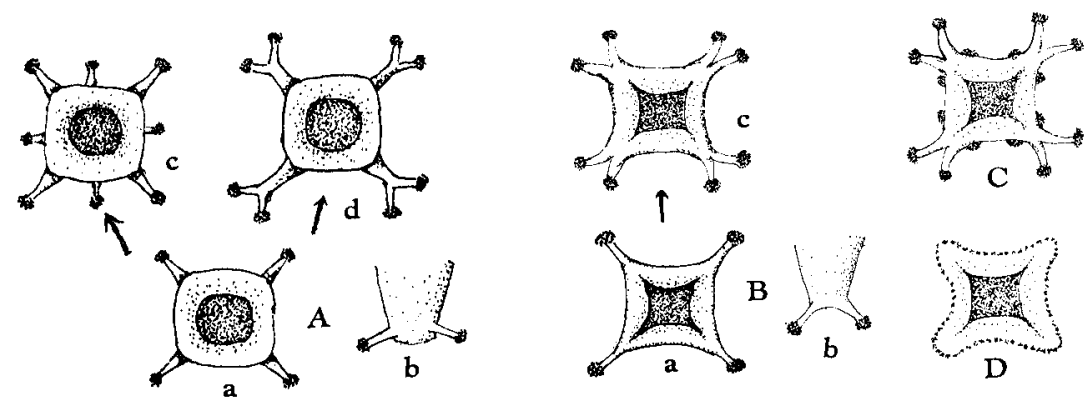

Fig. 8. Lips and oral tentacles of some medusae of the Filifera. A : a. Oral view of lips with 4 simple oral tentacles in young Cytaeis (Cytaeidae) and Bougainvillia (Bougainvilliidae), $b$. Lateral view of the tip of manubrium in young Cytaeis and Bougainvillia, $c$. Oral view of lips of Cytaeis more advanced than in the stage $a, d$. Oral view of lips of Bougainvillia more advanced than in the stage $a$. B: $a$. Oral view of lips with 4 simple oral arms in Podocoryne (Hydractiniidae), $b$. Lateral view of the tip of manubrium in Podocoryne, c. Oral view of lips with 4 bifurcated oral arms in Podocoryne. C: Oral view of lips of Rathkea (Rathkeidae). D: Oral view of Turritopsis (Clavidae).

solitary polyp. Medusae and sporosacs are both present in this family. This family illustrates several types of polyps in these respects. However, the medusae are always similar; they have solid clustered tentacles, branched oral tentacles and interradial gonads. The fossil medusa, Solnhofenistomides stechowi, a closely related form of the recent Kollikeria, is found in the Upper-Jurassic stratum in Germany. As stated above, the family has at least two types of colonies, creeping and arboreous, the former being coincided with colonies of the Cytaeidae. As to the medusae, the 4 perradial branched oral tentacles and the clustered solid marginal tentacles can be derived from the 4 simple oral tentacles and 4 single solid marginal tentacles of the Cytaeidae. The Cytaeid stage can be partly seen on the observation of metamorphosis of Bougainvilliid medusae. But in the Cytaeidae, instead of bifurcating the per- 
radial oral tentacles, the interradial new series of the tentacles arises at just upper level of the perradial one. The Eudendriidae with slightly modified polyps from these of Bougainvilliidae have always well-developed arboreous colonies. They have no free-medusae but sporosacs alone. The family seems to indicate a family which developed as arboreous colonies from the Bougainvilliidae.

The Hydractiniidae have creeping clolnies somewhat like Cytaeidae but are highly differentiated in showing polymorphism and in having well-chitinized skeleton and spines. Many fossils of the family are discovered in the Mesozoic. The family indicates elavoration of evolution as a colonial group from a related group of the Cytaeidae. The family has sporosacs of different types and unitary free medusae. Medusae are fairly similar to those of the Cytaeidae in having solid marginal tentacles which are generally more than 4 in number. They have no oral tentacles, but the four-sided lips are elongated, sometimes bifurcated and ended in nematocyst knobs, the character partly coincided with lips of the Rathkeidae. The Rathkeidae coincide with the Bougainvilliidae in the possession on clustered solid tentacles and also agree with the Hydractiniidae in having four-sided lips, with short stalked nematocyst knobs. The polyps are creeping and seem to form simple colonies. Their systematic position is not clear. In spite of so clear difference in polyps, the medusae of Clavidae are somewhat similar to those of Hydractiniidae in having solid not-clustered marginal tentacles and nematocyst knobs on the four-sided mouth, which are, however, smaller and distributed on the whole margin of lips. Besides, the medusae have axial ocelli on tentacle bases. The ocelli are not present in the medusae of the families, Cytaeidae, Rathkeidae, Hydractiniidae and some of Bougainvilliidae. At present solitary Clavids are found in Japan (not published). In consideration of the features of the families above mentioned, the writer propose here a genealogical tree of some families belonging to the Filifera.

In closing the writer's heartiest gratitude must be expressed to $H$. M. the Emperor who generously permitted the writer to study in his laboratory, and also placed his material at the writer's disposal. The writer's thanks must be extended to Messrs. H. Tsujimura aud U. Shimizu of the laboratory for the help in the research, and also to Dr. P. L. Kramp, Zoological Museum in Copenhagen, for his kindness in sending specimens used in this study.

\section{REFERENCES}

KomaI, T. 1931. On the hydroid stage of Cytaeis japonica UCHIDA. Annot. Zool. Jap. 13, 255258.

Kramp, P. L. 1928. Papers from Dr. Th Mortensen's Pacific Expedition, 1914-16. XLIII. Hydromedusae 1. Anthomedusae. K. Vidensk. Selsk. Dansk. naturh. 85, 27-64. 
1-469.

MAAs, O. 1909. Japanische Medusen. Abh. K. Bayer. Akad. Wiss, Suppl.-Bd. 1, 1-52, p1. 1-3. NAGAO, Z. 1964. The life-cycle of the hydromedusa, Nemopsis dofleini MAAs, with a supplementary note on the life-history of Bougainvillia superciliaris (L. AGAssiz). Annot. Zool. Jap., 37 , p. $153-162$.

REES, W. J. 1956. A revision of the hydroid genus Perigonimus M. SARS, 1846. Bull. British Mus. Zoology, 3', 335-350.

1957. Evolutionary trends in the classification of capitate hydroids and medusae. Bull. British Mus. Zoolog, 4, 455-534, p1. 12-13.

1962. Hydroids of the family Cytaeidae L. Agassiz, 1862. Bull. British Mus. Zoology, $8,381-400$, pl. 10-11.

UChidA, T. 1927. Studies on Japanese medusae 1. Anthomedusae. Jour. Fac. Sci. Imp. Univ. Tokyo, sec. 4. Zoology, I, p. 145-241, pl. 10-11.

1930. Beiträge zur Kenntnis der Japanischen Hydromedusen. Zool. Anz. 88, 329-335.

1938. Report of the Biological survey of Mutsu Bay 32. Medusae from Mutsu Bay (Revised Report). Sci. Rep. Tohoku Imp. Univ. Biology, 13, 37-46.

1938a. Medusae in the vicinity of the Amakusa Marine Biological Station. Bull. Biogeogr. Soc. Japan, 8, 143-149.

VAnnuCCI, M. \& W. J. ReEs 1961. A revision of the genus Bougainvilia (Anthomedusae). Bol. Inst. Ocean. 1 1, p. 57-100. 